\title{
THE INFLUENCE OF ELECTRICAL PULSES ON THICK FILM (DU PONT 1421 BIROX) RESISTORS
}

\author{
J.M. KOZLOWSKI and M. TANCULA \\ Institute of Electron Technology, Technical University of Wroclaw, 50-370 Wroclaw, Poland
}

(Received May 22, 1981; in final form October 20, 1981)

\begin{abstract}
This paper presents data on the effect of electric pulses on thick film resistors made using Du Pont 1421 Birox resistor pastes.

Resistance changes during the application of the electric pulses were investigated. Two types of change were observed: reversible and irreversible (i.e. catastrophic).

In order to illustrate the causes of these changes, observations of the film on a scanning electron microscope were made. Microcracks were observed in the film, which were mostly responsible for the permanent resistance changes.
\end{abstract}

\section{INTRODUCTION}

The application of electronic systems to pulse work requires a knowledge of the processes taking place in the circuit elements, particularly the resistors, which can be exposed to high temporary stresses. For this reason pulse method investigations were carried out on thick film resistors, ${ }^{1-3}$ based on Du Pont technology and paste.

A bridge method for detecting resistance change was used during the application of the electric impulses. ${ }^{4}$ This method enabled an analysis of the processes occurring in the film to be made and gave the possibility of the observation of the phenomena for a wide range of stresses and pulse durations.

In this paper an interpretation of the causes of the observed changes is discussed.

\section{EXPERIMENT}

Thick film resistors of initial resistance $R_{x o}\left(R_{x o}=\right.$ $90 \Omega \pm 5 \%) 1 \mathrm{~mm}$. long by $1.5 \mathrm{~mm}$. wide, produced on the basis of Du Pont paste (1421 BIROX) were used. The test pattern is shown in Figure 1.96\% $\mathrm{Al}_{2} \mathrm{O}_{3}$ ceramic, $0.55 \mathrm{~mm}$. thick was used as a substrate. The resistance changes of the sample were studied using the measurement system shown in Figure 2(a). ${ }^{4}$ The bridge was activated by rectangular pulses generated from a stabilized voltage supply $\left(U_{s}=140 \mathrm{~V}\right)$. A change of up to $3 \%$ of the power dissipated in the test resistor, $R_{x}$, was obtained by the use of a resistor of the value $R_{N}=1.4 \mathrm{R}_{x o m i n}$ in series with the investigated resistor.

The power dissipated $P_{x}$ in the test resistors is obtained from the relation, Eq. 1, the internal resis- tance of the stabilized supplier being assumed to be approximately equal to zero.

$$
P_{x}=U_{s}^{2} \frac{R_{x}}{\left(R_{x}+R_{N}\right)^{2}}
$$

This relation is shown in Figure 2(b). The resistance $R_{N}$ was chosen in order to obtain minimum changes of the power dissipated in the test resistors during the investigations. The relation, Eq. 2, was used to obtain the value of $R_{N}$

$$
\frac{P_{x \max }-P_{x}}{P_{x \max }}=\left(\frac{1-\frac{R_{N}}{R_{x}}}{1+\frac{R_{N}}{R_{x}}}\right)
$$

Figure 2(b) is a curve of power dissipated in the test resistor, $P_{x}$, as a function of resistance, $R_{x}$, and defines the terms used. The power dissipated in the test resistor is about 80 times greater than the recommended maxjmum power. Using a constant power pulse, it was

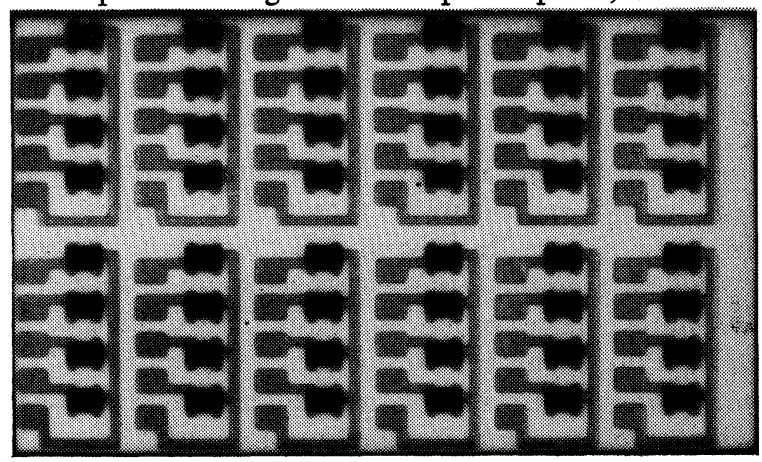

FIGURE 1 Test pattern of resistors. Resistor dimensions: length $1.0 \mathrm{~mm}$; width $1.5 \mathrm{~mm}$. 


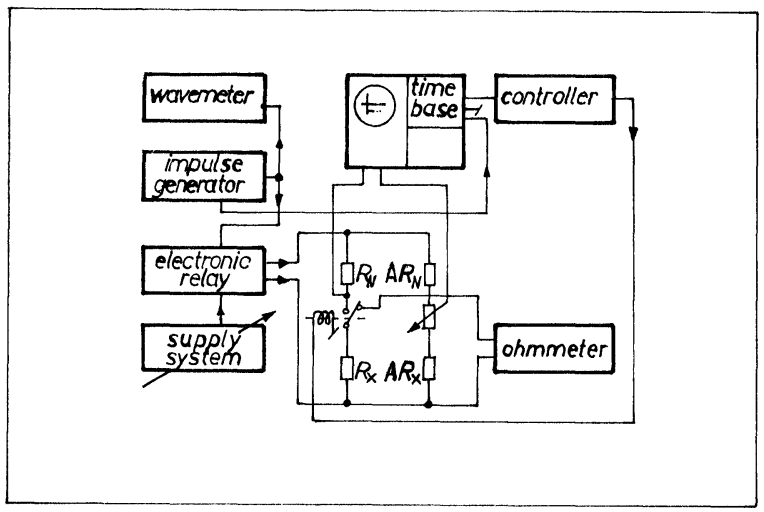

FIGURE 2(a) Measurement system. ${ }^{4} R_{x}$ is the test resistor.

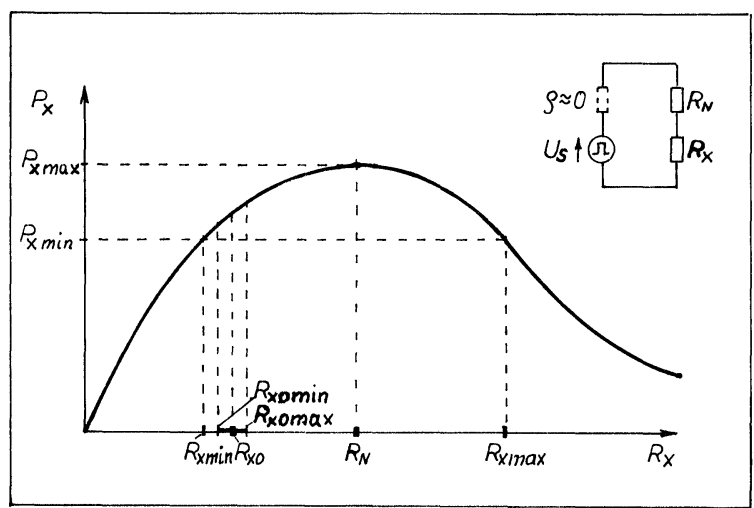

FIGURE 2(b) Power dissipated in the test-resistors as a function of resistance.

possible to keep the thermal energy constant which simplified the analysis of the resulting effects.

The time measurement of the observed voltage deviations of the bridge were carried out using a Tektronix Memory oscilloscope, the results on which were redrawn to determine the relation:

$$
f(t)=\frac{\Delta R_{x}}{R_{x o}}=\frac{R_{x}(t)}{R_{x o}}-1
$$

where $R_{x o}$ is the value of the test resistor at $t=0$.

\section{RESULTS}

Figure 3a presents a typical graph obtained on the oscilloscope, and Figure $3 \mathrm{~b}$ presents the redrawn graph. On Figure $3 \mathrm{~b}$ three stages of resistance change can be distinguished. In the first stage, up to time $t_{1}$, reversible changes produced by the thermal behaviour of the film, (Temperature coefficient of resistance), were observed. Irreversible resistance changes occurred after a certain energy supplied to the resistor was reached, i.e. after time $t_{1}$. This irreversible change was observed in terms of a sudden increase of resistance in the time range $t_{1}$ to $t_{2}$. Finally, after reaching a maximum in resistance at a time $t_{2}$, the resistance decreased down to a time $t_{3}$, when catastrophic destruction of the resistor occurred. By interrupting the applied pulse at different points along the time axis, scanning microscope observations were obtained.

(Figures 4 to 9 inclusive).

In the first stage, during which the reversible temperature changes were observed, no macroscopic changes were detected. (Figure 5a, b, c.)

The second stage, characterized by an irreversible resistance increase, was accompanied by the appearance of microcracks. (Figure 6a, b, c.). The width of the cracks was noted as being comparable with the diameter of the metallic particles in the resistor body. As time $(t)$ was increased the resistance, and also the density of the microcracks, increased. (Figure 7a, b).
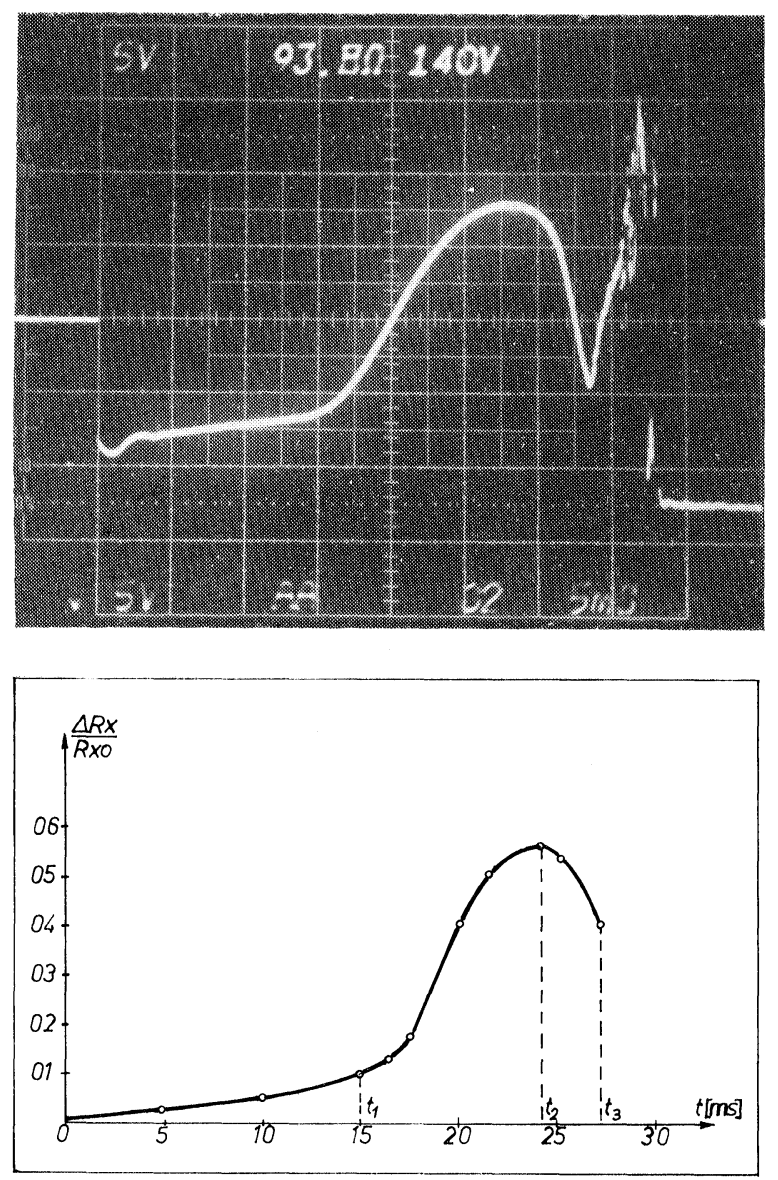

FIGURE 3 Out of balance bridge voltages obtained during pulse testing (a) Oscilloscope trace. (b) Relative resistance change. 

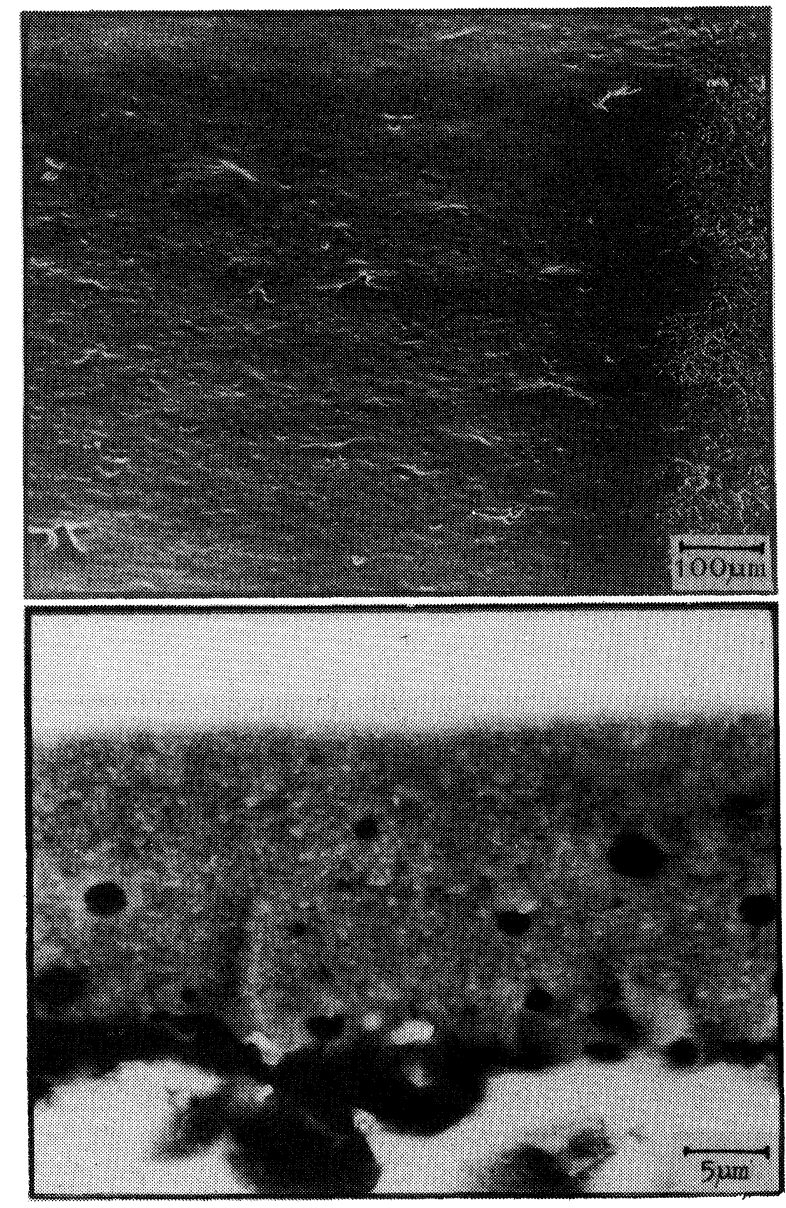

FIGURE 4 SEM micrographs showing the film before investigation. (a) Film surface. (b) Film cross section.

The next stage of resistance change was characterized by a sudden decrease in resistance. The causes of this phenomenon might be due to the improvement of the contacts between the boundaries of the cracks that had been created as well as the effects of local temperature breakdowns. (Figure $8 \mathrm{a}, \mathrm{b}, \mathrm{c}$.). The surfaces along microcracks are shown in Figure 8c. These surfaces were obtained by breaking the resistor. Finally exceeding the glass softening temperature $\left(t=t_{3}\right)$, led to the destruction of the resistor (Figure 9a, b, c.).

\section{CONCLUSIONS}

The following conclusions can be drawn from the investigations:-

1) Studies conducted on a great number of samples confirmed the reproducibility of the observed effects.
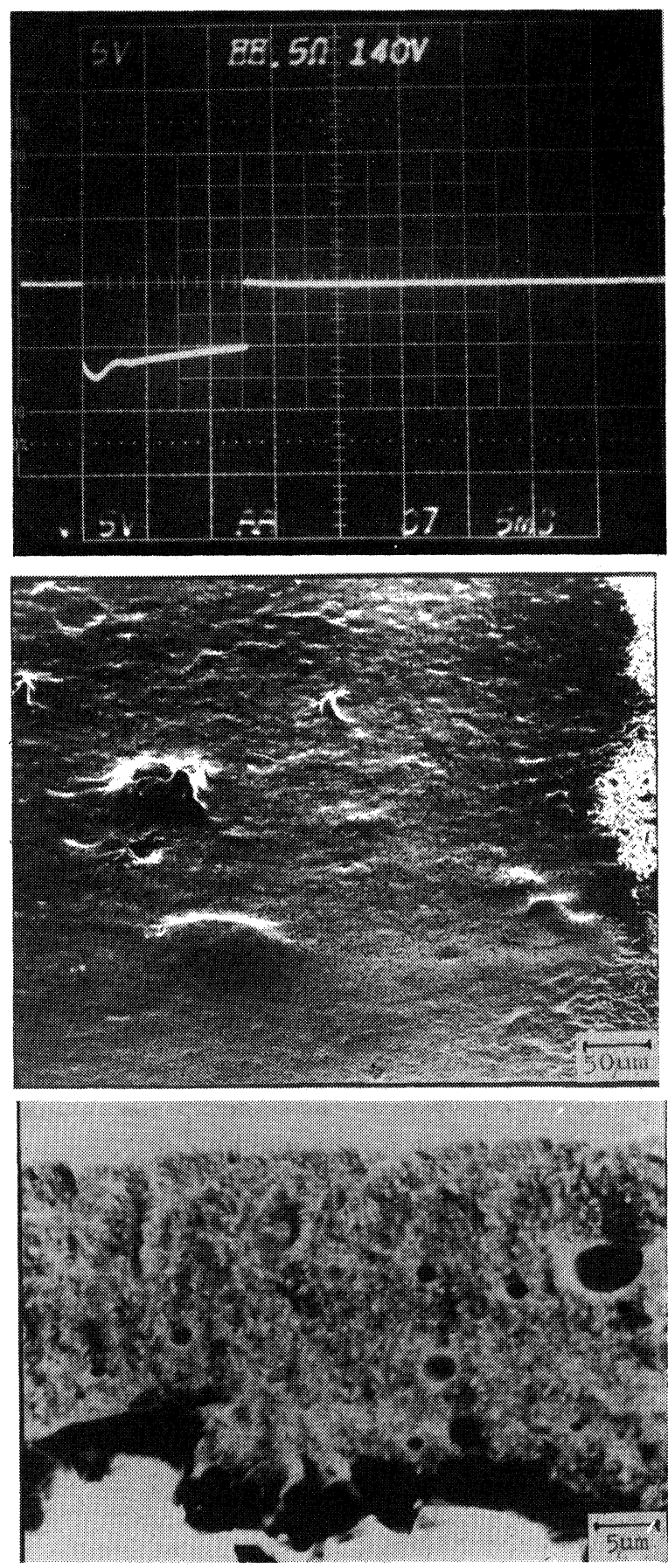

FIGURES 5 to 9 Out of balance bridge voltage and related SEM micrographs of film at successive stages of the application of electrical pulses to thick film resistors.

FIGURE $5 \quad t<t_{1}$

Fig. 5(a) Oscilloscope trace. Fig. 5(b) Film surface. Fig. 5(c) Film cross-section 

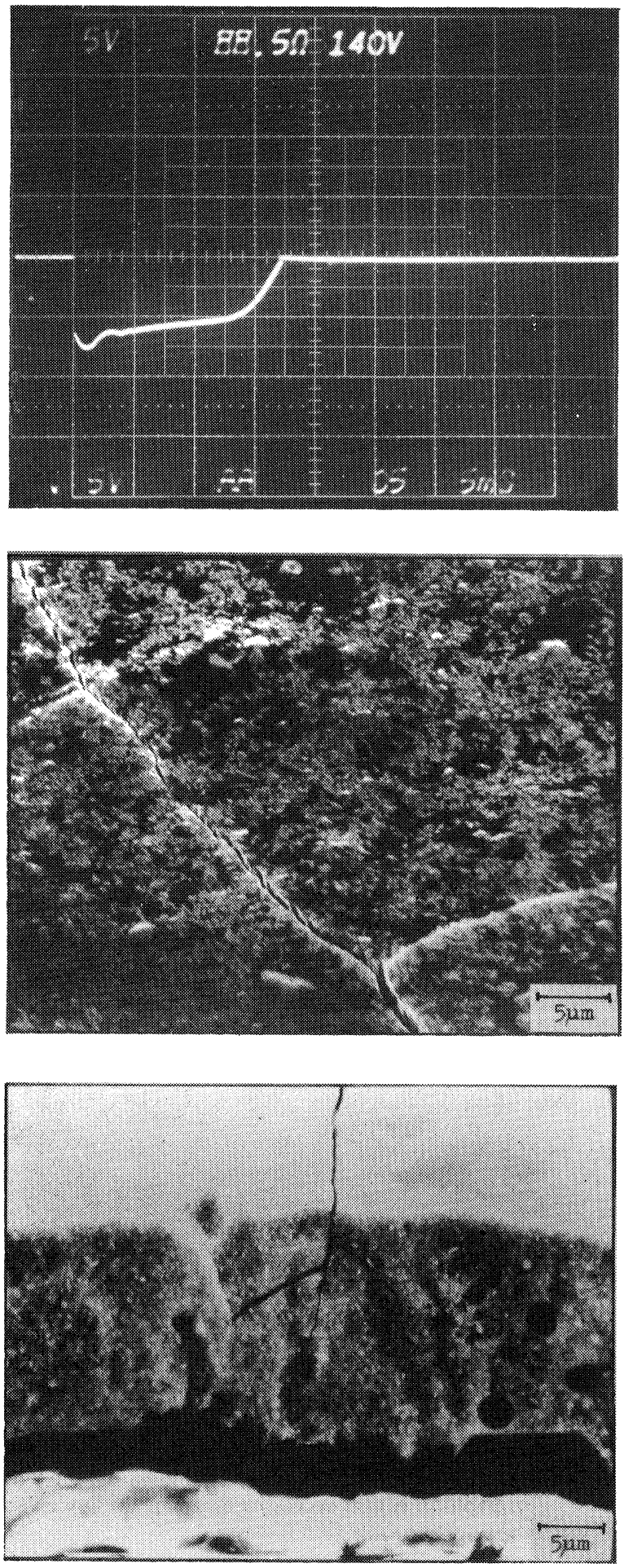

FIGURE $6 t_{1}<t \leqslant t_{2}$

Fig. 6(a) Oscilloscope trace. Fig. 6(b) Film surface. Fig. 6(c) Film cross-section
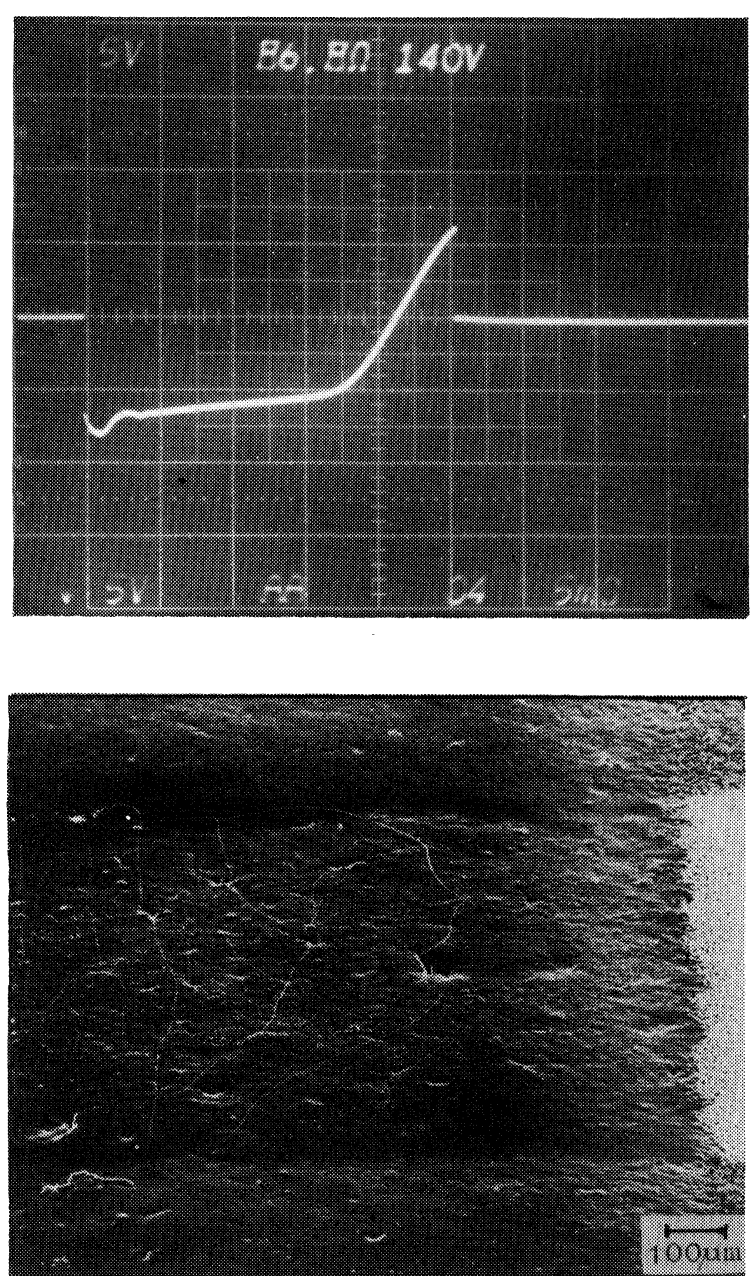

FIGURE $7 t_{2}<t<t_{3}$

Fig. 7(a) Oscilloscope trace. Fig. 7(b) Film surface

2) Both reversible (TCR) and irreversible resistance changes occurred. The irreversible changes occurred after a certain energy had been supplied to the film, i.e. after time $t_{1}$.

3) The irreversible changes were associated with macroscopic changes in the films, namely the appearance of microcracks. These appeared to be due to local stresses caused by the temperature gradient.

4) The improvement of the contacts between the boundaries of the cracks that have been created as well as local temperature breakdowns caused a decreasing of the resistance in the time range from $t_{2}$ to $t_{3}$.

5) After the glass softening temperature was exceeded, total destruction of the films occurred. 

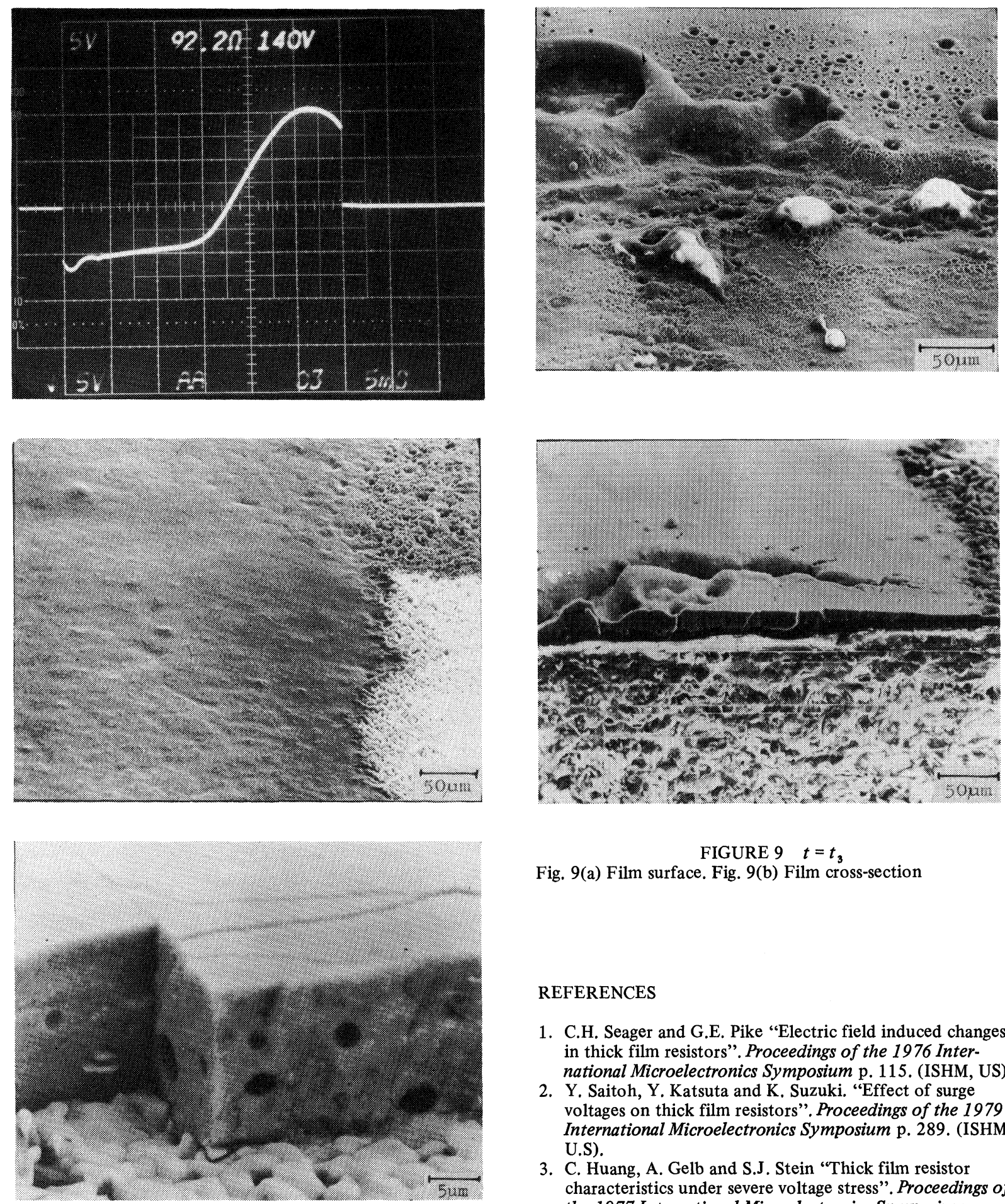

FIGURE $9 \quad t=t_{3}$

Fig. 9(a) Film surface. Fig. 9(b) Film cross-section

\section{REFERENCES}

1. C.H. Seager and G.E. Pike "Electric field induced changes in thick film resistors". Proceedings of the 1976 International Microelectronics Symposium p. 115. (ISHM, US).

2. Y. Saitoh, Y. Katsuta and K. Suzuki. "Effect of surge voltages on thick film resistors". Proceedings of the 1979 International Microelectronics Symposium p. 289. (ISHM, U.S).

3. C. Huang, A. Gelb and S.J. Stein "Thick film resistor characteristics under severe voltage stress". Proceedings of the 1977 International Microelectronics Symposium p. 65. (ISHM, US).

FIGURE $8 t_{2}<t<t_{3}$

Fig. 8(a) Oscilloscope trace. Fig. 8(b) Film surface. Fig. 8(c) Film cross-section

4. M. Tańcula "Pulse heating on properties of metal films". II Ogólnopolskie Sympozjum Szczyrk 10 23-29 (1975). 

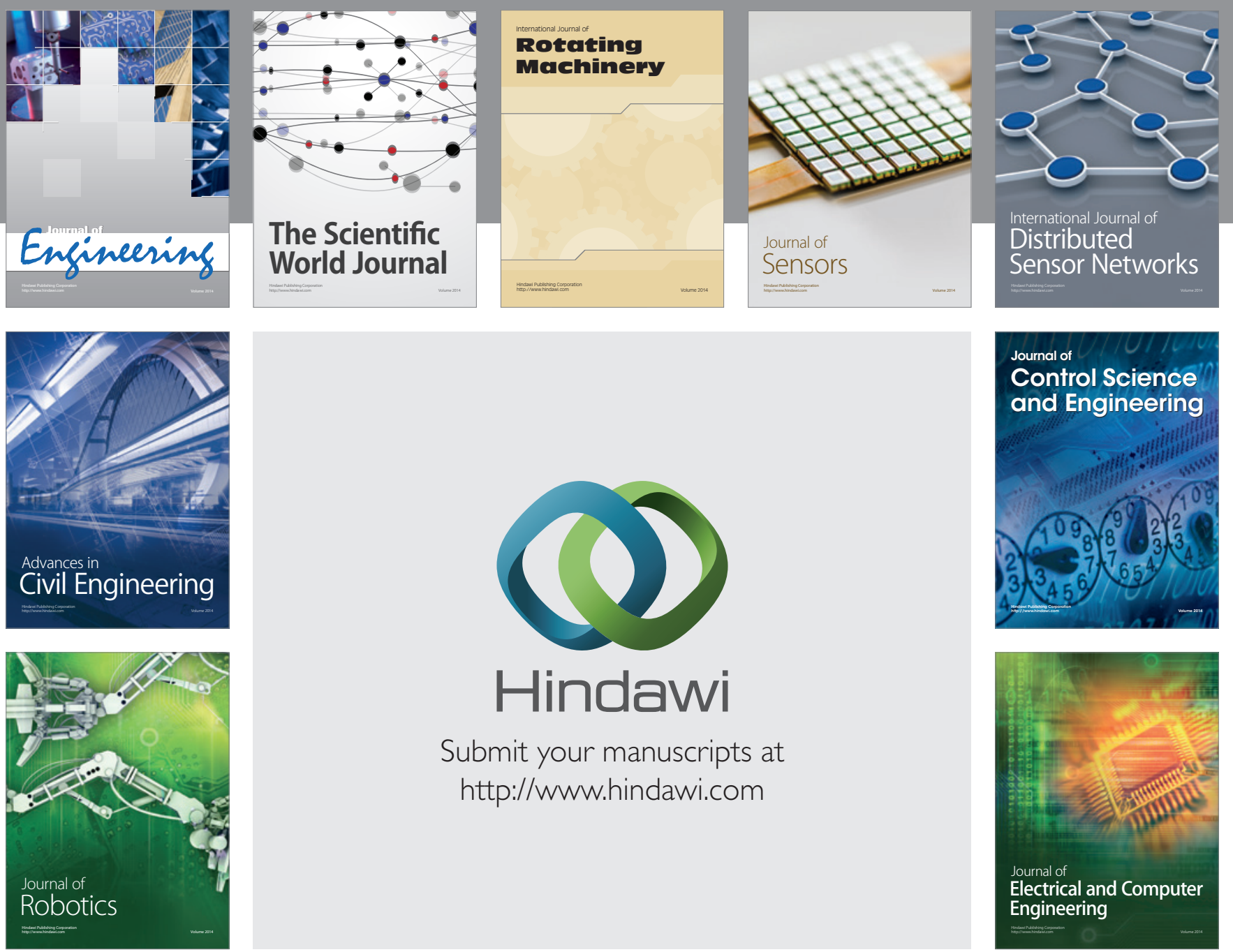

Submit your manuscripts at

http://www.hindawi.com
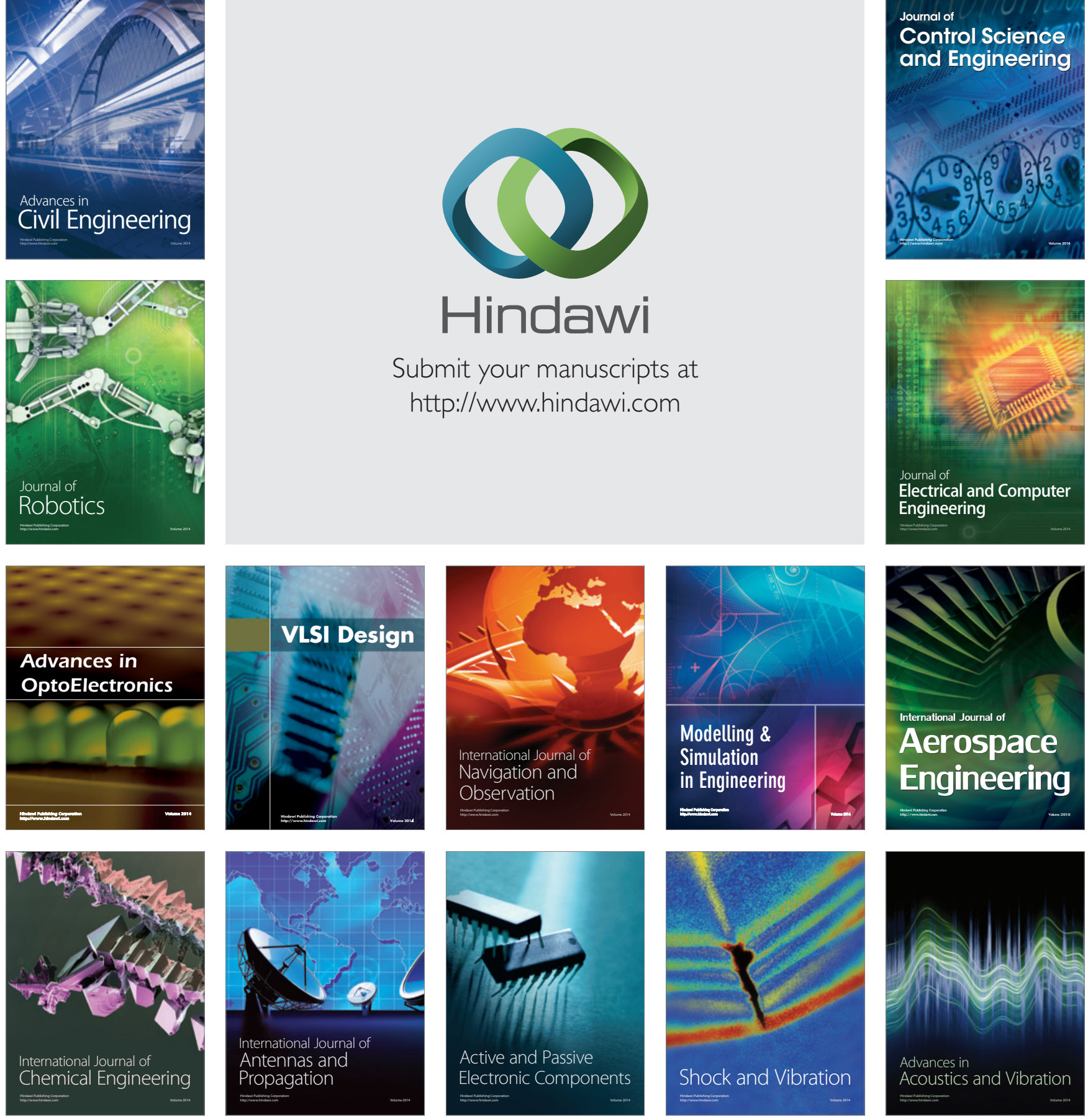